\title{
A BURETTE FOR THE ACCURATE MEASUREMENT OF GAS VOLUMES WITHOUT GAS CONNECTON TO A COMPENSATOR
}

\author{
By E. R. Weaver and Martin Shepherd \\ ABSTRACT
}

This paper describes a burette for measuring gas volumes, which embodies a novel compensator designed to eliminate errors of diffusion into the manometer. The burette is of the type having several bulbs of equal volume and a side arm for measuring fractional parts of these volumes. Mercury levels in the side arm are read by means of a vernier scale, permitting high accuracy within a comparatively short length. The burette proper is approximately $38 \mathrm{~cm}$ in length with a total capacity of $125 \mathrm{cc}$. An accuracy of $0.01 \mathrm{cc}$ is readily obtained.

The source of one of the common errors likely to occur in the measurement of gas volumes with the ordinary type of pressurecompensated burette is the diffusion of gas into the manometer. Careful technique requires the displacement of this gas by the confining liquid used in the manometer, but this is not totally accomplished in ordinary practice. If the last trace of diffused gas is not removed from the manometer arm adjacent to the burette, appreciable errors may result. The burette described in this paper embodies not only a sensitive compensating arrangement designed to eliminate diffusion errors, but also employs as an integral part of this compensating device a novel vernier scale for the accurate reading of gas volumes.

The subject may be advantageously developed by an initial discussion of the principle of operation, followed by notes on construction, assembly, and manipulation, and finally a report of results obtained in use.

The glass parts of the apparatus are shown by the line sketch (fig. 1) and the assembled apparatus by the photograph (fig. 2). Its operation may be briefly explained by reference to the line drawing, while details of construction and general assembly become evident from a study of the photograph.

\section{PRINCIPLE OF OPERATION}

The burette proper consists of five 20 cc pear-shaped bulbs (11) forming the main stem, and a side arm (10) for the measurement of fractional parts of the bulbs. A metal scale parallel to the side arm is graduated to $25 \mathrm{cc}$ in $0.1 \mathrm{cc}$ divisions. (See fig. 2.) The scale 


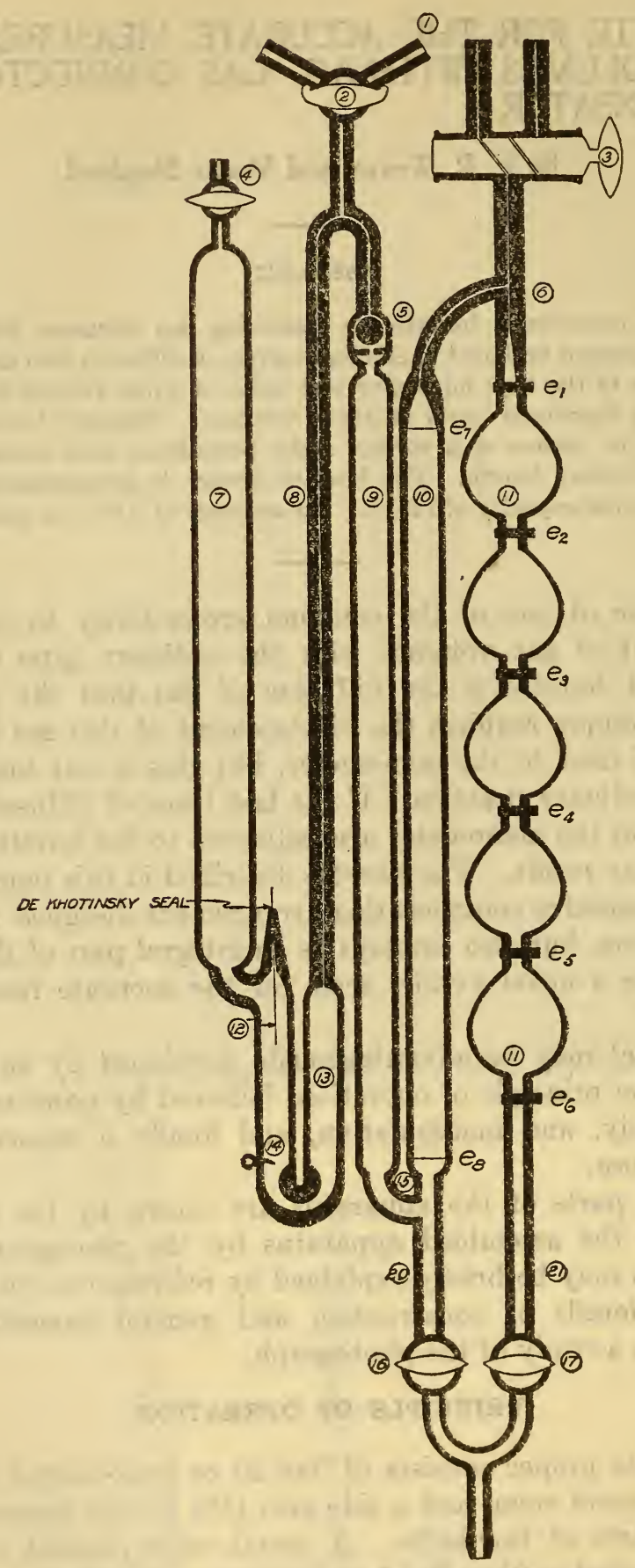

FIG. 1.-Diagram of burctte 
Scientific Papers of the Bureau of Standards, Vol. 22

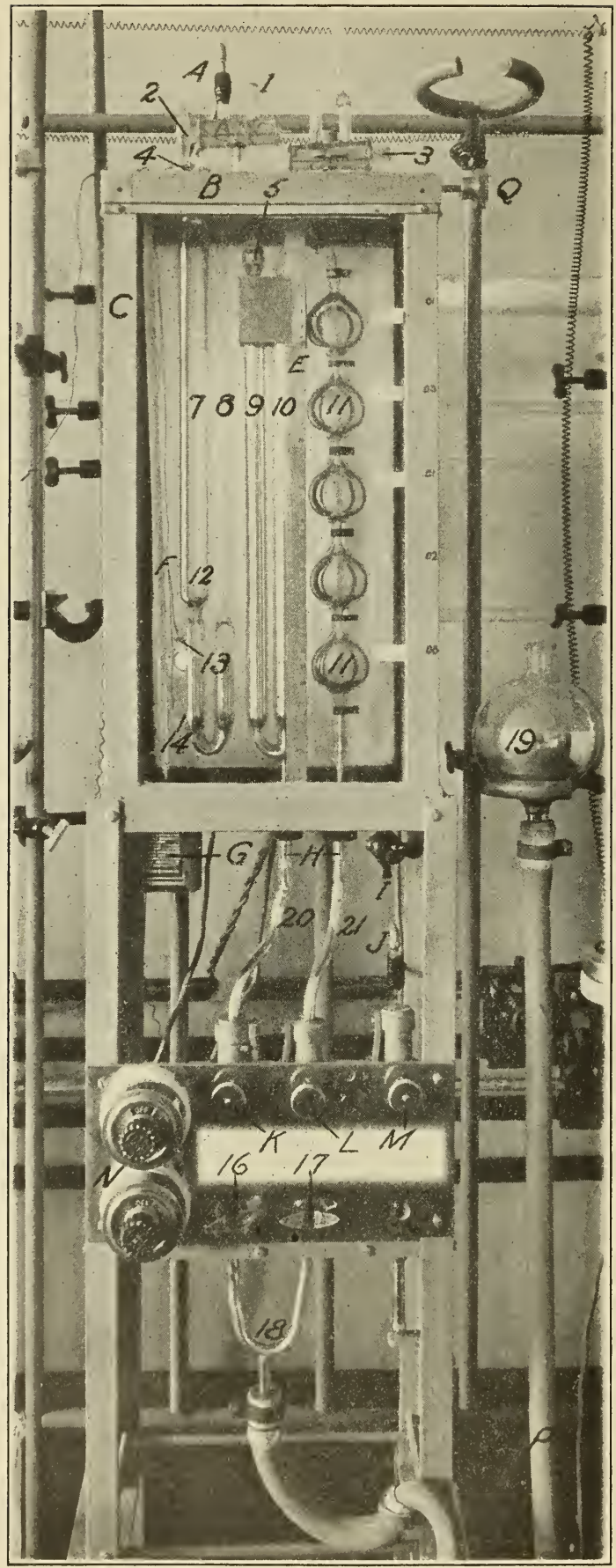

FIG. 2.-Burette assembly 
is adjusted so that the volume bounded by etch marks $E_{1}, E_{7}$, and the stopcock (3) equals a convenient whole number of $\mathrm{cc}(2 \mathrm{cc}$ in the present instance). A double collar, which carries a vernier in contact with the metal scale, incloses and can be slid along tubes (9) and (10). In reading the mercury level in either of these tubes this collar is adjusted to just cut off the light above the meniscus in the same way as in a barometer of the better grade. A float valve (5) prevents mercury from (9) entering the manometer (13), which is connected to (9) through a capillary tube (8) and to the inclosed compensator ( 7$)$. The manometer is provided with a pointed platinum contact (12), which indicates the balance by closing a circuit containing a miniature lamp and battery. A condenser connected across contacts (12) and (14) minimizes sparking at the mercury surface. The platinum contact may be sealed in with De Khotinsky cement to permit removal for cleaning.

The usual errors caused by diffusion into the manometer are eliminated, since the $U$ tube formed by arms (9) and (10) interposes a mercury seal between a gas contained in the burette proper and the manometer.

The condition for proper pressure balance is evident; the mercury menisci in (9) and (10) must be at exactly the same level at the instant the lamp indicates the manometer balance. This adjustment is very simply attained by approximately balancing the intermediate manometer (9-10) against the manometer (13), with the compensator at atmospheric pressure, by means of the leveling bulb connected to the $Y(18)$, and obtaining final adjustment by a suitable method of introducing small pressure changes in the volume between arm (9) and the manometer.

The manipulation for balancing this intermediate manometer formed by arms (9) and (10) is best explained with reference to the photograph. For simplicity, the glass parts have been numbered in the photograph to correspond to the sketch, while metal and other auxiliary parts are lettered. Stopcock (2) is shown as a two-way in the photograph, but was changed to correspond to the $Y$ type shown in the sketch. A one-sixteenth-inch outside diameter copper tube is cemented to one outlet of cock (2) and terminates at $J$ where it is joined to a length of rubber nitrometer tubing provided with a compression screw $M$. By means of this screw a mercury column in $J$ is made to rise and fall, effecting the minute pressure changes needed for final adjustment of the system. The two burette outlets (20) and (21) are connected to similar lengths of tubing equipped with compression screws $K$ and $L$. The volumes between manometer and arm (9), and between stopcock (2) and $J$, are reduced to a minimum by the capillary construction employed, thus insuring a quick pressure balance. 
Before beginning a series of measurements which are to be compared, cocks (2) and (4) are opened to the atmosphere to bring the volume of gas in compensator ( 7$)$ initially to atmospheric pressure. A subsequent volume measurement then involves the following steps:

(1) With cock (2) open to the atmosphere, the gas is drawn into the burette through cock ( 3 ) by manipulating leveling bulb (19) connected through nitrometer tubing $P$.

(2) The intermediate manometer formed by arms (9) and (10) is used to adjust the gas volume to the required number of bulbs and to an approximate balance against the atmosphere.

(3) Cocks (16) and (17) are closed, and compression screw $L$ is used to adjust the mercury column to the etch mark (collar) on the stem between the bulbs.

(4) Cock (2) is turned to first connect $J$ to the atmosphere, then to connect $J$ to the volume between the manometer and arm (9). Compression screws $K$ and $M$ are then used to balance the manometer (13), and the intermediate manometer (arms (9) and (10)) simultaneously. Compression applied at $M$ depresses the mercury level in arm (9) with a corresponding rise in arm (10). Compression applied at $K$ raises the mercury levels in both arms (9) and (10), that in (9) at a greater rate than that in (10). These conditions make possible a quick adjustment of the pressure. A second adjustment of $L$ is made before the final balance.

The pressure in the burette then equals the compensator pressure.

It is surprising that the time required for this double compensation is not much longer than that required for adjusting the usual apparatus with a Petersen compensator. Once the operator has become trained in the manipulation, a careful compensation usually requires between 30 and 60 seconds, following the first rough adjustment by the leveling bulb. It is, of course, quite advantageous to arrange the compensator pressure, when fixed for a series of corresponding measurements, to closely duplicate atmospheric pressure, since the intermediate manometer $(9-10)$ is used for the first rough adjustment, and is most conveniently balanced directly against the existing atmospheric pressure.

The lamp which indicates when the manometer is balanced is shown at $F$, with its battery at $G$, and switch at $N$. The balance across (9) and (10) is sighted by shutting off light at the extreme tips of the mercury menisci by the sliding collar $D$, which carries the vernier over the scale $E$. The collar $D$ is lowered or raised by a gear engaging with a worm screw of coarse pitch located behind (10), and, in turn, geared to handwheel $Q$. (This actuating arrangement, not shown in detail, is similar to the worm gear used on chain balances.) 
The vernier and scale, with the burette assembly, are mounted on a frame $B$ which slips snugly into the water bath $C$, constructed of angle iron and plate glass cemented thereto with the Bureau of Fisheries aquarium cement. The side and back glass plates are ground, and a showease lamp mounted behind provides ideal diffused light for adjusting menisci in the burette arms and the stems between bulbs.

The burette leads (20) and (21) are brought through packing glands $H H$ in the metal plate which forms the bottom of the water jacket. Since the Bureau of Fisheries' cement, which is used as a packing material, remains soft and plastic, the removal of the burette is possible at any time. Two-way stopcocks (not shown) sealed to these leads provide a means for cleaning the burette with acids without dismounting the unit.

The burette is supported at the top by $U$ clamps on a crosspiece, and rigid pins are provided at the seal $(6)$ and the $U$ formed below cock (2) upon which the burette rests as a zero level. The position of the burette with relation to the scale can be checked by reading the value of a fine etch mark at the top of arm (10) and further by comparing graduations on the gearing mechanism attached to $Q$.

Metal parts are nickel plated to prevent corrosion. When in constant use no difficulty develops. If, however, the mechanism remains idle the portions of the gearing immersed in water may corrode and stick. For this reason the water should be drained from the tap $I$ if the burette is not to be used for several weeks.

Copper collars blackened with sodium sulphide are used instead of etch marks on the stems between the bulbs. These collars are designed to clamp with absolute security around the stem. They are employed on account of the ease with which a mercury column can be adjusted to just shut off light at the bottom edge of the collar and tip of the meniscus. The precision of adjustment is much greater than adjustment to the ordinary etch mark, as shown by Table 1, which gives the results of calibration of the same bulb between etch marks and between collars. The calibrations were made by weighing mercury, corrections being made according to the values given in Smithsonian Physical Tables, seventh revised edition, page 72.

The data of Table 1 form a basis for judging the accuracy with which the level of the mercury menisci in arms (9) and (10) can be read by the use of the vernier slide (which acts as a movable collar), and shows the accuracy to be greater than that with which the present vernier can itself be read.

The source of major error in the use of the burette lies in the double compensation and adjustment of the menisci in arms (9) and (10) to an identical level. The vernier slide method of reading levels in arms (9) and (10) compares directly with the accuracy 
obtained in reading a barometer so equipped, except that in the present instance two levels must be read and a simultaneous zero adjustment made on both. That this can not be accomplished with the accuracy of the actual compensation itself is shown by a comparison with the results of the Weaver and Ledig ${ }^{1}$ weight burette which indicate a figure of about 0.001 cc as the limit of accuracy in a double compensation, where the manometer is balanced by use of the platinum contact and light circuit, insuring high precision if the contact is kept clean.

The error caused by neglecting the differential expansion of the. glass and the metal scale with temperature change can be disregarded.

The present burette gives results agreeing to better than $0.01 \mathrm{cc}$, as shown in Tables 2,3 , and 4 . Table 2 shows repeated measurements of a fixed volume in the side arm, the pressure balance being destroyed between each reading. Table 3 gives the results of measurement of fixed volumes which were transferred between two adjoining bulbs and the side arm. Table 4 shows the measurement of a fixed volume measured as a whole and then divided into several portions for measurement, the sum of the parts being checked against the whole.

The data indicate a satisfactory agreement.

\section{SUMMARY}

TABLE 1.-The degree of precision with which a gas volume can be determined by adjusting a mercury column between: $(A)$ Two ordinary etch marks ${ }^{a}$ and $(B)$ two blackened collars

[Vols. determined by weight of mercury, corrected according to Smithsonian Physical 7th ed. Tables p. 72 Internal bore of stems of bulb approximately $7 \mathrm{~mm}$.]

[A and $\mathrm{B}$ were not identical volumes]

\begin{tabular}{|c|c|c|c|}
\hline \multicolumn{2}{|c|}{ A } & \multicolumn{2}{|c|}{ B } \\
\hline \multicolumn{2}{|c|}{$\begin{array}{c}\text { Adjustment between } \\
\text { etch marks }\end{array}$} & \multicolumn{2}{|c|}{$\begin{array}{c}\text { Adjustment between } \\
\text { blackened collars }\end{array}$} \\
\hline $\begin{array}{l}\text { Volumes } \\
\text { (corrected) }\end{array}$ & $\begin{array}{l}\text { Deviation } \\
\text { from } \\
\text { average }\end{array}$ & $\begin{array}{l}\text { Volumes } \\
\text { (corrected) }\end{array}$ & $\begin{array}{l}\text { Deviation } \\
\text { from } \\
\text { average }\end{array}$ \\
\hline $\begin{array}{c}c c \\
10.030 \\
10.029 \\
10.029 \\
10.030 \\
10.031\end{array}$ & $\begin{aligned} & c c \\
& 0.000 \\
&-.001 \\
&-.001 \\
& .000 \\
&+.001\end{aligned}$ & $\begin{array}{c}c c \\
10.0048 \\
10.0045 \\
10.0047 \\
10.0047 \\
10.0046\end{array}$ & $\begin{array}{r}c c \\
+0.0002 \\
+.0001 \\
+.0001 \\
+.0001 \\
.0000\end{array}$ \\
\hline
\end{tabular}

a Not of the finest, but the average ordinary work supplied by apparatus firms.

I J. Am. Chom. Soc., 42, p. 1177; 1920. 
TABLE 2.-Reproducibility of volume measurement on side arm of burette

[Successive readings made after destroying balance of compensation and bringing to a new balance]

\begin{tabular}{|c|c||c|c|}
\hline $\begin{array}{c}\text { Volume in } \\
\text { cc }\end{array}$ & $\begin{array}{c}\text { Deviation } \\
\text { from } \\
\text { average }\end{array}$ & $\begin{array}{c}\text { Volume in } \\
\text { cc }\end{array}$ & $\begin{array}{c}\text { Deviation } \\
\text { from } \\
\text { average }\end{array}$ \\
\hline 18.15 & 0.00 & $18.145 \ldots$ & -0.005 \\
$18.15 \ldots .$. & .00 & $18.15 \ldots . .$. & .00 \\
18.15 & .00 \\
$18.155 . .$. & +.00 & $18.15 \ldots . .$. & .00 \\
$18.15 \ldots . .00$ & .00 & $18.15 \ldots$ & .00 \\
\hline
\end{tabular}

TABLE 3.-Reproducibility of volume measured on side arm and bulbs, by alternating volumes between side arm and two successive bulbs, with consequent destruction of compensation balance between readings

SERIES 1

\begin{tabular}{|c|c|c|c|c|}
\hline Reading No. & $\begin{array}{l}\text { Side arm } \\
\text { volume }\end{array}$ & $\underset{\text { volume }}{\text { Bulb }}$ & $\begin{array}{c}\text { Total } \\
\text { volume }\end{array}$ & $\begin{array}{l}\text { Deviation } \\
\text { from aver- } \\
\text { age total } \\
\text { volume }\end{array}$ \\
\hline${ }^{1}{ }^{1}{ }^{2}{ }^{2}$ & $\begin{array}{r}4.44 \\
24.46 \\
4.45 \\
24.46 \\
4.44 \\
4.45 \\
4.45 \\
24.46\end{array}$ & $\begin{array}{r}20.01 \\
20.01 \\
.00 \\
20.01 \\
20.01 \\
20.01 \\
.00\end{array}$ & $\begin{array}{l}24.45 \\
24.46 \\
24.46 \\
24.46 \\
24.45 \\
24.46 \\
24.46 \\
24.46\end{array}$ & $\begin{array}{r}-0.008 \\
+.002 \\
+.002 \\
+.002 \\
+.008 \\
+.002 \\
+.002 \\
+.002\end{array}$ \\
\hline
\end{tabular}

SERIES 2

\begin{tabular}{|c|c|c|c|c|}
\hline 1 & $\begin{array}{r}4.45 \\
24.47 \\
4.45 \\
24.46 \\
4.46 \\
24.47 \\
4.45\end{array}$ & $\begin{array}{l}\text { 40. } 03 \\
\text { 20. } 01 \\
40.03 \\
\text { 20. } 01 \\
40.03 \\
20.01 \\
40.03\end{array}$ & $\begin{array}{l}44.48 \\
44.48 \\
44.48 \\
44.47 \\
44.49 \\
44.48 \\
44.48\end{array}$ & $\begin{array}{r}0.00 \\
.00 \\
.00 \\
+.01 \\
+.01 \\
.00 \\
.00\end{array}$ \\
\hline
\end{tabular}

SERIES 3

\begin{tabular}{|c|c|c|c|c|}
\hline${ }^{2}{ }^{2}$ & $\begin{array}{r}24.68 \\
4.69 \\
24.69 \\
4.70 \\
24.68 \\
4.70 \\
24.68\end{array}$ & $\begin{array}{l}\text { 40. } 03 \\
60.01 \\
40.03 \\
60.01 \\
40.03 \\
60.01 \\
60.01\end{array}$ & $\begin{array}{l}64.71 \\
64.70 \\
64.72 \\
64.71 \\
64.71 \\
64.71 \\
64.71\end{array}$ & $\begin{array}{r}0.00 \\
-.01 \\
+.01 \\
.00 \\
.00 \\
.00 \\
.00\end{array}$ \\
\hline
\end{tabular}

SERIES 4

\begin{tabular}{|c|c|c|c|c|}
\hline 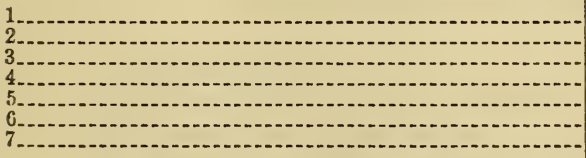 & $\begin{array}{r}\text { 24. } 665 \\
24.66 \\
4.65 \\
24.66 \\
4.65 \\
24.66 \\
4.65\end{array}$ & $\begin{array}{l}60.01 \\
60.01 \\
80.02 \\
60.01 \\
80.02 \\
60.01 \\
80.02\end{array}$ & $\begin{array}{l}84.675 \\
84.67 \\
84.67 \\
84.67 \\
84.67 \\
84.67 \\
84.67\end{array}$ & $\begin{array}{r}0.00 \\
.00 \\
.00 \\
.00 \\
.00 \\
.00\end{array}$ \\
\hline
\end{tabular}

SERIES 5

\begin{tabular}{|c|c|c|c|c|}
\hline 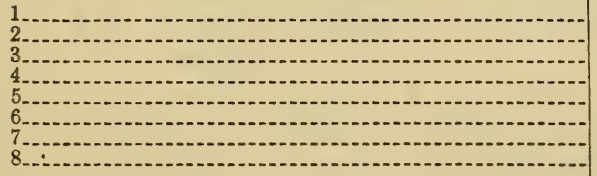 & $\begin{array}{l}\text { 4. } 61 \\
\text { 4. } 61 \\
24.665 \\
24.66 \\
4.61 \\
24.67 \\
24.67 \\
24.66\end{array}$ & $\begin{array}{l}100.075 \\
100.075 \\
80.02 \\
80.02 \\
100.075 \\
80.02 \\
80.02 \\
80.02\end{array}$ & $\begin{array}{l}104.685 \\
104.685 \\
104.685 \\
104.68 \\
104.685 \\
104.69 \\
104.69 \\
104.68\end{array}$ & $\begin{array}{r}0.000 \\
.000 \\
.000 \\
-.005 \\
.000 \\
+.005 \\
+.005 \\
-.005\end{array}$ \\
\hline
\end{tabular}

1 Neglected. 
TABLE 4.-Measurement of a volume as a whole and as the sum of its parts

\begin{tabular}{|r|c|c|}
\hline Side arm volume & $\begin{array}{c}\text { Bulb } \\
\text { volume }\end{array}$ & $\begin{array}{c}\text { Combined } \\
\text { volume }\end{array}$ \\
\hline 23.39 & 100.075 & 123.465 \\
23.40 & 100.075 & 123.475 \\
\hline A verage & -123.47 \\
\hline 13.24 & 0 & 13.24 \\
17.39 & 24.01 & 24.35 \\
8.46 & 40.03 & 28.47 \\
\hline Total volume. & 20.01 & 28.47 \\
\hline
\end{tabular}

A burette has been designed for the measurement of gas volumes to $0.01 \mathrm{cc}$ or better, which possesses about half the average length of the ordinary type, and eliminates any error of diffusion of the gas under measurement into the manometer.

Washington, February 4, 1927. 